\title{
An investigation of fracture toughness and dynamic mechanical analysis of polymer nano-composites
}

\author{
G.U. Raju ${ }^{1 *}$, C. G. Rajeswari ${ }^{2}$, R. Balannavar ${ }^{3}$, K.G. Kodancha ${ }^{4}$ \\ ${ }_{1 * 2,3,4}$ Department of Mechanical Engineering, B.V. Bhoomaraddi College of Engineering and Technology, Hubli, INDIA \\ "Corresponding Author: e-mail: raju_gu@bvb.edu,Tel +91-9448717310
}

\begin{abstract}
The study deals with development of a new composite material with an objective to increase the mechanical and thermal properties. The proposed work involves the preparation of novel polymer based composite material reinforced with cenosphere and multi walled carbon nanotubes (MWCNTs) and to investigate fracture toughness and dynamic mechanical properties. MWCNTs have high tensile strength which contributes to increase in strength of composite as well as the load transfer capability. The 20 weight $\%$ of cenosphere and upto $0.5 \mathrm{wt} \%$ of MWCNTs are used for the study. Dynamic mechanical analysis and fracture toughness tests of the composite were carried out. It was found that fracture toughness of the sample with 0.2 wt $\%$ MWCNT increased by $12 \%$ than the epoxy cenosphere composite. The results obtained by experimental test are compared with the simulation results. Thermal properties obtained by DMA have shown better thermal stability. The SEM analysis was carried out to study the interfacial bonding between the fiber-matrix and also to substantiate the fracture toughness result.
\end{abstract}

Keywords: MWCNT, Cenosphere, Dynamic Mechanical Analysis, Fracture toughness

DOI: http://dx.doi.org/10.4314/ijest.v10i2.4

\section{Introduction}

Polymer composites have found great importance in this emerging world due to their high strength to weight ratio. According to Lee et al. (1967) epoxy resin has vast applications, although it has some drawbacks such as brittleness, low strength, stiffness, low resistance to the fatigue crack propagation and poor fracture toughness. It needs some reinforcement so that the properties are enhanced. Allaoui et al. (2002) note that the addition of rigid particles like carbon nanotubes shows some improvements in the properties of the epoxy by increase in modulus and strength. Research suggests that MWCNTs due to their high aspect ratio and unique properties such as high strength, stiffness, thermal and electrical conductivity will help in forming a better composite.

Some studies have showed that the fracture toughness of epoxy resin could be improved by the addition of the fly ash particles as fillers. Hussain et al. (2016) has carried out a research work which shows the enhancement in the mechanical properties by the addition of MWCNTs in epoxy resin. Jalageri et al. (2015) has showed in the work that the addition of cenosphere particles along with MWCNTs showed a significant change in the mechanical properties like tensile strength, flexural strength and the impact strength. Padal et al. (2014) states that addition of the nanoparticles in the epoxy showed better mechanical and thermal properties like storage modulus, glass transition temperature, compared to the plain epoxy. Divya et al. (2015) showed that the mechanical \& thermal properties showed synergism when both cenospheres and MWCNT were added and hence led to their improvement. In an investigation done by Arijit et al. (2011) the damping properties of cenosphere filled polypropylene composites enhanced and is particularly observed in $10 \mathrm{wt} \%$ cenosphere. In the composites relative to the soft PP-phase, $30 \%$ increase in the storage modulus was observed. Although a nominal decrease in tensile strength was observed, the tensile modulus increased up to 43\%. Alumina and silica are the main constituents of fly ash that improve the composite properties. Cenospheres are found to some extent in the form of hollow spherical particles in fly ash which help to maintain low density values for the composites as suggested by M R Doddamani et al. (2011). Geethamma et al. (2005) carried out dynamic mechanical analysis which concludes that the poor interfacial bonding of the reinforcing particles with the base material was related to the dissipation of more energy and vice versa. Different experimental 
tests like thermal analysis technique, dynamic mechanical analysis (DMA) and fracture tests have been carried out to study the effect of carbon nanotubes dispersion on the mechanical properties of the epoxy-cenosphere composite.

\section{Experimental Details}

\subsection{Materials \\ 2.1.1. Epoxy Resin}

They are a class of reactive pre-polymers and polymers that contain two or more epoxy groups. It has high mechanical properties due to low shrinkage and relatively unstressed structures. It also assists in the formation of strong unstrained adhesive bonds. The cured epoxy usually has a good thermal and dimensional stability. They absorb low moisture because of the moisture barriers. They also have good insulating properties viz., dielectric strength and tracking resistance. They also possess good electrical properties for various range of temperatures. It is used in the composites in various applications like construction, electronics, packaging and as a protective coating in aerospace applications. Epoxy L12 resin was used in the study with hardener K6.

\subsubsection{Cenosphere}

Cenospheres are exclusive free flowing powders of tiny spheres collected from coal ash. Their amount is based on the carbon and iron content present in the fly ash. Due to higher particle strength, ultra-low density, impermeability they are used for various applications. Cenosphere of 75 to 150 Microns size was supplied from Sarlachem Ahmedabad. It is used as the primary reinforcement material in the composite.

\subsubsection{MWCNT}

MWCNTs are of special interest to the industry in the current world. Their excellent properties of strength to weight ratio make them a good fit for the family of nano-composites. They also exhibit good thermal and electrical conductivity, strength, stiffness and toughness. Such properties of these materials make them an important part of various applications such as electromagnetic shielding, coatings, catalysts, textiles and fibers, fuel cells, aerospace, medical implants and many more. MWCNTs was purchased from Quest International, Bangalore. It is used as the secondary reinforcement material. Benefit of the addition of primary reinforcement cenosphere is to improve mechanical and chemical properties of the composite. Also, it controls the material cost of the resin matrix. Secondary reinforcement MWCNT is added to increase the strength and stiffness of the composite.

\subsection{Preparation}

The Epoxy L12 Resin was heated for 15-20 min in a beaker to reduce its viscosity. Appropriate amount of cenosphere and MWCNTs as per the calculations, are added to the epoxy in a beaker and stirred well for the homogeneous dispersion of both primary and secondary reinforcement materials in the epoxy for 20-25 min using the magnetic stirrer. The composition in a beaker was kept in the ultra-sonicator for degassing and homogenous dispersion of the nanoparticles in the base material, as mentioned by Shubham et al. (2015). The mixture was poured into the mould after the addition of hardener and cured at $30^{\circ} \mathrm{C}$ for 24 hours. The mixing ratio of Epoxy and K6 Hardener was 10:1. The specimens are designated as ECC0 for epoxy (80\%), cenosphere (20\%) and MWCNT(0\%),ECC1 for epoxy(79.9\%), cenosphere (20\%) and MWCNT (0.1\%) and so on up-to ECC5 with epoxy (79.5\%), cenosphere (20\%) and MWCNT $(0.5 \%)$.

\subsection{Experimental tests}

\subsubsection{Dynamic mechanical analysis(DMA)Test}

The test is conducted as per ASTMD4065.The specimen size is $55 \mathrm{~mm} \times 10 \mathrm{~mm} \times 5 \mathrm{~mm}$. Parameters such as frequency, amplitude and temperature range were given as inputs. Testing was carried out at ambient temperature to $150^{\circ} \mathrm{C}$, at which the material starts to degrade. Experiments were conducted by applying a small cyclic deformation to a sample over a wide temperature range. The following experimental conditions were used to analyze the composite specimen, Jianing et al. (2012). Heating rate $-5^{\circ} \mathrm{C} / \mathrm{min}$, frequency - $1 \mathrm{~Hz}$, maximum load range - up to $5 \mathrm{~N}$, deformation mode -dual cantilever, deformation amplitude - $5 \mu \mathrm{m}$ and cooling liquid nitrogen. The influence of weight percent of MWCNT (0.1- 0.5\%) of ECC polymer composites has been studied using a dynamic mechanical analysis test. DMA results show the changes in a composite material, i.e. storage modulus, loss modulus and tan delta with respect to temperature and revealed useful information about its thermal transition.

\subsubsection{Fracture toughness}

An attempt has been made to find the fracture toughness of newly developed nano-composite material using SENB (single edge notch bending) specimen for Mode-I. The specimen of dimensions 100x30x13 mm and a $45^{\circ} \mathrm{V}$ notch of width $0.3 \mathrm{~mm}$ and depth $13 \mathrm{~mm}$ was prepared as shown in Figure 1. The specimen was tested on the computerized universal testing machine at uniform crosshead velocity of $1 \mathrm{~mm} / \mathrm{min}$. Using load displacement diagram and at the onset of crack propagation the fracture load was obtained. Using Equation (1), mode-I critical fracture was calculated. Four specimens of each composition were tested to obtain the fracture toughness value and average is used as a fracture toughness of material. 


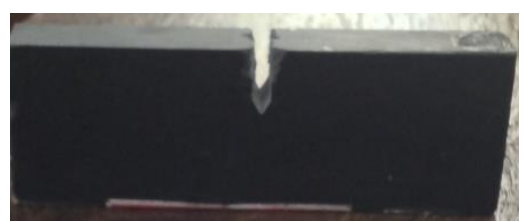

Figure 1: Composite specimen for fracture toughness test

$$
\mathrm{K}_{\mathrm{IC}}=\frac{P S}{B W^{1 / 2}} f(a / w)
$$

\section{Results and Discussion}

\subsection{DMA Test}

Glass transition temperature of the epoxy/cenosphere composite with MWCNTs measured by DMA is given in Table 1. Glass transition tempertature is often taken at the temperature of the maximum tan delta, Shubham et al.(2015) as shown in Figure 2. It was observed that $\mathrm{T}_{\mathrm{g}}$ of all the composite with MWCNTs is shifted towards the lower temperature compared to epoxy /cenosphere composite. The amount of energy needed is more with addition of MWCNTs due to high crosslink density. Adding 0.1wt.\% MWCNTs does not effect on the $\mathrm{T}_{\mathrm{g}}$ much, while adding $0.2 \mathrm{wt} \%$ MWCNTs led to increase in the $\mathrm{T}_{\mathrm{g}}$. It is due to the reason that presence of properly dispersed MWCNTs that are attached to the matrix molecule chains limit their motion, which ultimately increased $\mathrm{T}_{\mathrm{g}}$.

Table 1: Glass transition temperature for different samples

$\begin{array}{cc}\begin{array}{c}\text { Composite } \\ \text { specimen }\end{array} & \begin{array}{c}\text { Glass transition } \\ \text { temperature }\left(\mathbf{T}_{\mathbf{g}}\right)^{\circ} \mathbf{C}\end{array} \\ \text { ECC0 } & 84.00 \\ \text { ECC1 } & 88.67 \\ \text { ECC2 } & 91.33 \\ \text { ECC3 } & 83.37 \\ \text { ECC4 } & 87.03 \\ \text { ECC5 } & 79.08\end{array}$

Addition of $0.3 \mathrm{wt} \%, 0.4 \mathrm{wt} \%$ and $0.5 \mathrm{wt} \%$ caused a drop in the $\mathrm{T}_{\mathrm{g}}$ value.It is because of the agglomeration of MWCNTs and also proves that after $0.2 \mathrm{wt} \%$ MWCNTs will not diperse uniformly in base material. Due to this agglomeration there will be large number of voids between the molecules of the base material which leads to an increase in segmental motions in the base material network, therefore there is a decrease in the value of $\mathrm{T}_{\mathrm{g}}$, Putz (2008).

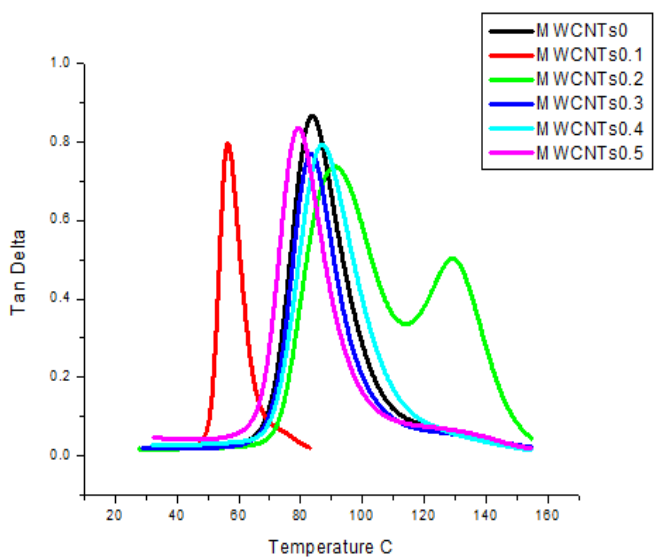

Figure 2: Tan Delta vs Temperature

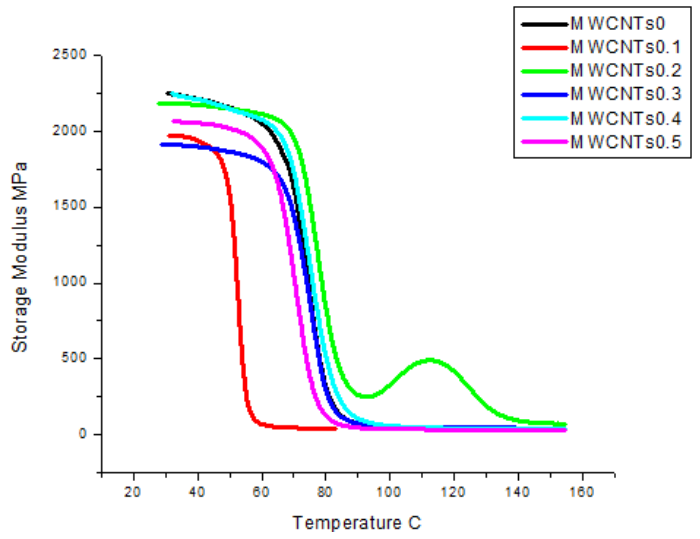

Figure 3: Storage modulus vs Temperature 


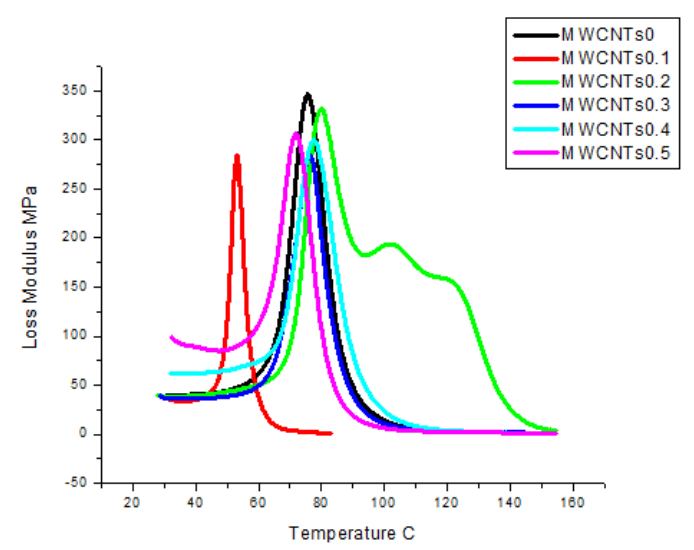

Figure 4: Loss modulus vs Temperature

The storage modulus of the composites for the different composition is shown in the Figure 3. It is observed that the storage modulus of the composition with $0.2 \mathrm{wt} \%$ MWCNT shows the highest value when compared to the other samples of different compositions. The storage modulus at the temperature of $100^{\circ} \mathrm{C}$ above the glass transition of all the samples, Jianing et al. (2012) was $328.3 \mathrm{MPa}$ and for the sample of ECC0 is $49.95 \mathrm{MPa}$. The value of storage modulus is enhanced by $84 \%$ when compared to the sample with ECC0.The modulus is increased due to high modulus of MWCNTs at $0.2 \mathrm{wt} \%$ which is properly dispersed in the epoxycenosphere composite.Similar work was carried out by the Shubam et al. (2015) which had revealed the same results that the addition of the MWCNTs increased the modulus when compared to that of plain polymer epoxy.The work carried out by Song et al. (2012) showed the same results that the addition of MWCNTs to the epoxy has improved the storage modulus and concluded that MWCNTs can incresase the cross link density of the composite. Loss modulus of the samples with the different composition is shown in the Figure 4. It is observed that the increase in temperature leads to increase in the loss modulus for the $0.2 \mathrm{wt} \%$ MWCNTs sample when compared to the plain epoxy-cenopshere and at $0.3 \mathrm{wt} \%$ of MWCNTs there is slight increase in the loss modulus .

\subsection{Fracture toughness}

Fracture toughness value of the epoxy /cenosphere composite with MWCNTs is obtained by experiment and is shown in Figure 5. From the Figure, it can be seen that there is increase in fracture toughness by $12 \%$ and $2 \%$ at $0.2 \%$ and $0.3 \mathrm{wt} \%$ of MWCNTs respectively when compared to ECC 0 . It is also observed that there is a decrease of fracture toughness at $0.1 \%$ and also for the $0.4 \%$ and $0.5 \%$ samples. Increase in the value of fracture toughness at $0.2 \%$ and $0.3 \%$ MWCNTs is due to proper dispersion of MWCNTs, as surface area of the MWCNTs is more, Domun et al. (2015) and also may be due to even distribution of load. However, beyond $0.3 \mathrm{wt} \%$ of MWCNTs there is no proper dispersion of the MWCNTs in the epoxy/cenosphere composite, as there is agglomeration of MWCNTs which results in ease of crack propagation through the specimen. It also results in the stress concentration in the agglomeration which may enhance the propagation of the crack in the specimen. The other reason for the agglomeration of MWCNTs is due to the high viscosity of the epoxy which limits the movement of MWCNTs as stated by Domun et al. (2015). Similar work carried out by Natarajan et al. (2014) on the epoxy glass fiber has shown the good result when compared to the plain epoxy composite. Research carried by Parween et al. (2013) on the sugar palm reinforced epoxy composite has shown that the addition of sugar palm has increased the fracture toughness value $1.25 \mathrm{MPa} \sqrt{\mathrm{m}}$, which is in good agreement with the present work. The maximum value of fracture toughness was found at $0.2 \%$ MWCNT and is $6.15 \mathrm{MPa} \sqrt{\mathrm{m}}$.

Analysis of the SENB specimen for the fracture toughness is also carried out using ABAQUS software. Due to symmetry of the specimen, half symmetry of the specimen is used for the analysis. The loads applied on the specimen were same as obtained in experiment. In the vicinity of the crack front fine mesh is used and appropriate boundary conditions were applied to meet the experimental requirements and are shown in Figure 5. Fracture toughness of the composite specimen was obtained from the simulation, compared with experimental results and are presented in the Figure 6.

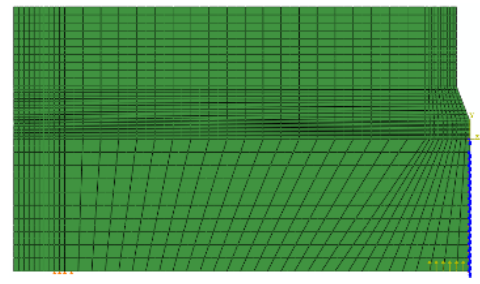

Figure 5: Model of composite specimen with meshing and boundary conditions 


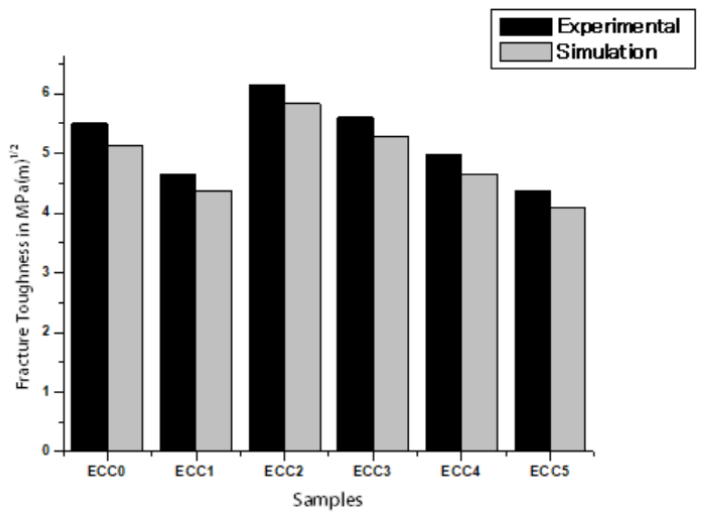

Figure 6: Results of fracture toughness

From the results obtained, error is within $10 \%$ indicates that both experimental and simulation results are in good agreement with respect to percentage error.

\subsection{SEM Analysis of composite specimens}

The surface morphology of epoxy-cenosphere-MWCNT composites are studied using Scanning electron microscope. SEM analysis helps in analysing the mode of dispersion of reinforcement material in the base matrix. Basically censophere and the MWCNTs are carbon particles, when the light is made to fall on the carbon particles it will reflect,which will indicate their presence in the base matrix. SEM image of each sample is shown in the Figure 7(a-f). It can be observed that in the sample with 0.2 and 0.3 wt $\%$ of MWCNTs, there is a better dispersion of nano fibers and beyond $0.3 \mathrm{wt} \%$, results in agglomeration of MWCNTs.

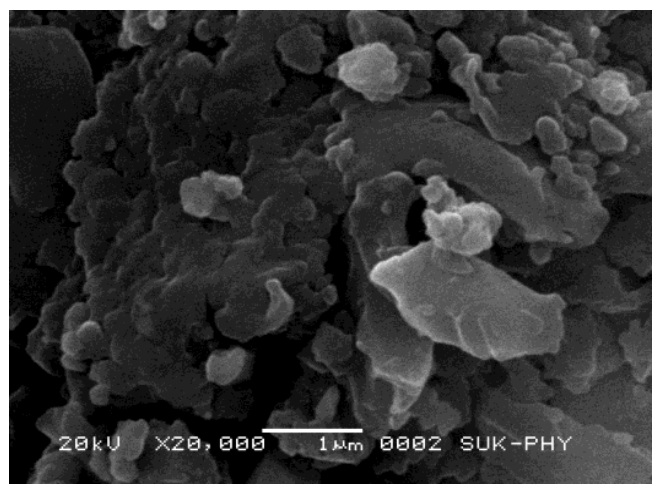

(a) $\mathrm{ECCO}$

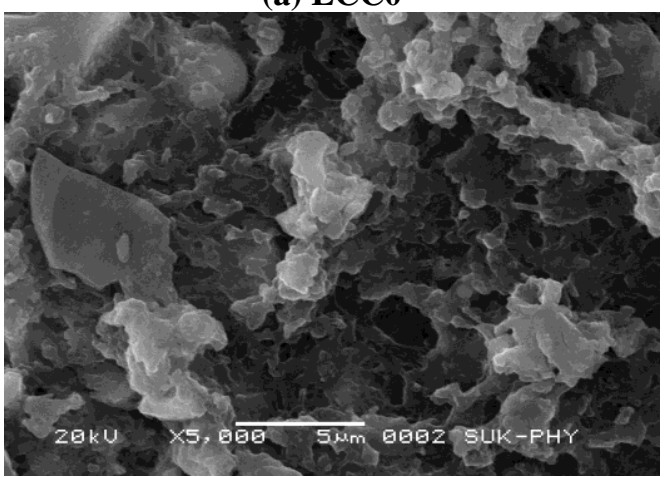

(c) $\mathrm{ECC} 2$

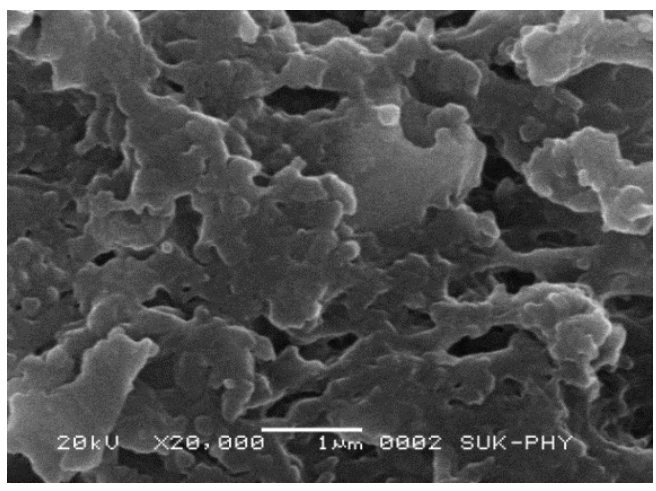

(b) ECC1

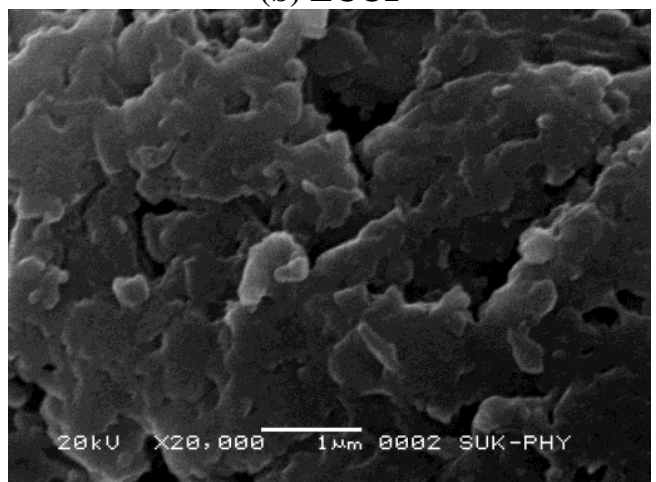

(d) $\mathrm{ECC3}$ 


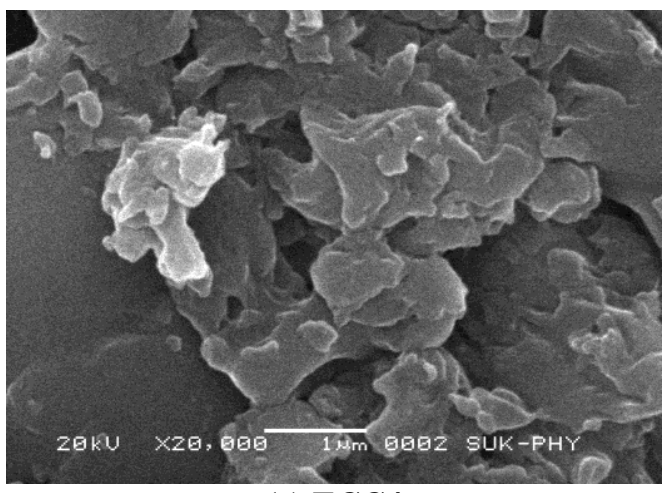

(e) ECC4

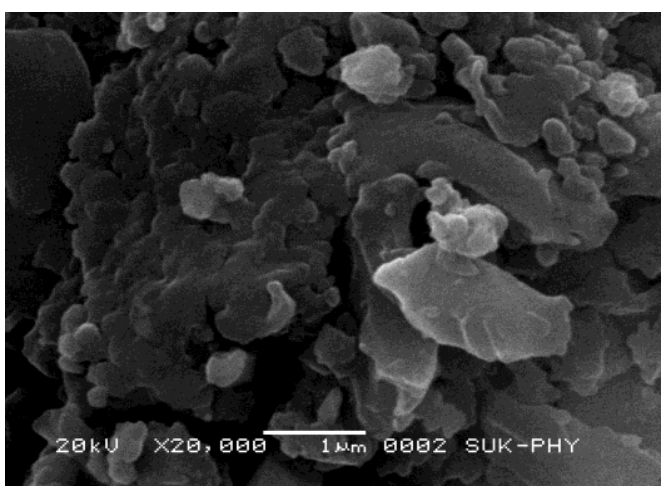

(f) ECC5

Figure 7(a-f): SEM image of the fracture surface of the samples

\section{Conclusion}

In the present work, dynamic mechanical analysis and using SENB geometry fracture toughness was investigated. From the DMA test, it has been observed that owing to the MWCNTs functionality, a strong interfacial bond and good dispersion reduced the mobility of the epoxy/cenosphere composite molecules around the MWCNTs and thus increased the thermal stability of the composites. Inclusions of MWCNTs as secondary reinforcement material into the epoxy and cenosphere composite has improved the fracture toughness of ECC2and ECC3 composites as there is a proper dispersion of MWCNTs. Further, owing to better dispersion and more surface area of MWCNTs, these composites carries more load. Beyond $0.3 \mathrm{wt} \%$ of MWCNTs fracture toughness was decreased as there is no proper dispersion of the MWCNTs in the composite and due to agglomeration of MWCNTs which results in ease of crack propagation through the specimen. It may also result in the stress concentration in the agglomeration region. The fracture toughness is increased by $12 \%$ in case of $0.2 \%$ MWCNTs which shows the improvement of mechanical properties with the addition of MWCNTs. From the DMA test, it was observed that $T_{\mathrm{g}}$ of all the composite with MWCNTs is shifted towards the lower temperature compared to epoxy /cenosphere composite. The amount of energy needed is more with addition of MWCNTs due to high crosslink density. Adding 0.1 and 0.2 , wt $\%$ of MWCNTs led to increase in the $\mathrm{T}_{\mathrm{g}}$. Also, the storage modulus for the specimen with $0.2 \mathrm{wt} \%$ MWCNT shows the highest value when compared to the other specimens. Further, these studies could be extended by carryingout surface modification to the MWCNTs that enhances the mechanical properties of nano-composites. Also, studies could be extended by carrying out post curing of the composite as it play important role in obtaining optimum mechanical and thermal properties of polymer based composites. Generally, glass transition temperature ( $\mathrm{Tg}$ ) increases with increasing post curing temperature.

\section{Nomenclature}

MWCNT- Multi walled carbon nano tubes

DMA-Dynamic mechanical analysis

ECC-epoxy-carbon nanotubes-cenosphere

SENB- Single edge notch bending

\section{References}

Allaoui A., Bai S., Cheng H.M., Bai J.B.2002. Mechanical and electrical properties of a MWNT/epoxy composite, Composite Science and.Technology, Vol. 62, pp.1993-1998.

Anderson T. L.,2005. Fracture Mechanics: Fundamentals and Applications, $3^{\text {rd } E d i t i o n, ~ C R C ~ P r e s s . ~}$

Das A, Bhabani K., Satapathy. 2011.Structural, thermal, mechanical and dynamic mechanical properties of cenosphere filled polypropylene composites, Materials and Design, Vol.32, pp.1477-1484.

Dehghan M., Al-Mahaidi R., Sbarski I. 2014. Thermo-mechanical characterization of MWCNTs-modified epoxy resin, International Journal of Chemical, Nuclear, Materials and Metallurgical Engineering, Vol. 8, No. 2, pp.111-116

Divya V.C., Ameen Khan M., Nageshwar Rao B., Sailaja R. R. N. 2015.Highdensitypolyethylene/cenosphere composites reinforced with multi-walled carbon nanotubes: Mechanical thermal and fire retardancy studies, Materials \& Design, Vol.65, pp.377-386.

Doddamani M.R., Kulkarni S.M. 2011. Dynamic response of fly ash reinforced functionally graded rubber composite sandwiches a Taguchi approach, International Journal of Engineering, Science and Technology Vol. 3, No. 1, pp.166-182.

Domun N., Hadavinia H., Zhang T., Sainsbury T., Liaghat G.H., Vahid S. 2015.Improving the fracture toughness and the strength of epoxy using nanomaterials - a review of the current status, Nanoscale, Vol.7, pp10294-10329. 
Geethamma V.G.,Kalaprasad G., Groeninckx G., Thomas, S.2005. Dynamic mechanical behavior of short coir fiber reinforced natural rubber composites, Composites:Part A, Vol. 36, No. 11, pp.1499-1506.

Hussain M. T, Shivakumar GoudaP.S., Siddhalingeshwar I.G., Kodancha K.G. 2016.Effect of alcoholic treated MWCNT on tensile behavior of epoxy composite, International Journal of Engineering, Science and Technology, Vol. 8, No. 1, pp. 57-63.

Jalageri H. B., Raju G.U., Kodancha K.G.2015. Experimental investigations on mechanical properties of cenosphere/MWCNT reinforced polymer nanocomposites, American Journal of Materials Science, Vol. 5, No. 3C, pp.101-106.

Gao J., Li J., Brian C.B., Zhao S., Henrik H., Linda S.S. 2012. The mechanical properties of epoxy composites filled with rubbery copolymer grafted SiO, Polymers, Vol.4, pp.187-210.

Lee H., Neville K., 1967. Handbook of Epoxy Resins, $1^{\text {stEdition, McGraw-Hill: New York, USA. }}$

Natarajan K., Padma C.B.2014. Study of mechanical and morphological properties of glass fiber reinforced modified epoxy composites, International Journal of Research in Engineering and Technology, Vol. 3, No. 1, pp.1-6.

Padal K.T.B., Srikiran S., Nagendra PS. 2014.Dynamic mechanical and thermal properties of jute nano fibre reinforced polymer composite, $5^{\text {th }}$ International \& $26^{\text {th }}$ All India Manufacturing Technology, Design and Research Conference (AIMTDR 2014) IIT Guwahati, Assam, India.

Parween A.K., Omer S. Z., Basim A. K., Zainab S.R. 2013. Fracture Toughness of Sugar Palm Fiber Reinforced Epoxy Composites, International Journal of Science and Research (IJSR), Vol.2(12), pp.273-279.

Putz K.W. 2008. Effect of cross-link density on interphase creation in polymer nanocomposites, Macromolecules, Vol. 41(18), pp. 6752-6756.

Shubham G., Ariful R. 2015. Effect of the carbon nanotubes on the thermo -mechanical properties of glass fiber/epoxy laminated nanocomposites, International Journal of Scientific and Research Publications, Vol. 5, No. 2, pp.1-5.

Song W., Li C.Q., Lin L., Chen Y. 2013. Research on the mechanical and thermal properties of MWCNTs/CF reinforced epoxy resin matrix composite patch, Physics Procedia, Vol. 50, pp 405-409.

\section{Biographical notes}

C.G. Rajeswari has completed her B.E in Mechanical engineering in 2016 from B.V.B. College of Engineering and Technology, Hubli, Karnataka

R. Balannavar has completed his B.E in Mechanical engineering in 2017 from B.V.B. College of Engineering and Technology, Hubli, Karnataka.

G.U. Raju is Associate Professor in the School of Mechanical Engineering of KLE Technological University, Hubballi, Karnataka, India. He has 24 years of experience in teaching and research and has several technical papers to his credit. His current area of research includes Natural fiber polymer composites, Finite element analysis and Vibration analysis.

K.G. Kodancha, obtained M. Tech.in Design Engineering from Indian Institute of Technology, Chennai, India in 2002 and Ph. D from Visvesvaraya Technological University, Belgaum, Karnataka, India in 2012. He has 24 years of teaching and research experience and has several technical papers to his credit. He is presently working as Professor and Coordinator, M. Tech, Machine Design, in the Department of Mechanical Engineering, B.V.B. College of Engineering and Technology, Hubli, Karnataka. His research interests include stress analysis and fracture mechanics.

Received July 2017

Accepted April 2018

Final acceptance in revised form April 2018 